investigation of the problems in question. He concluded that the value of $\Delta \Gamma$ at the absolute zero is equal to zero for all reactions involving only pure liquids and solid substances, that the molal heat capacity of any gas at the absolute zero is a iunction only of the number of atoms in the molecule. He concluded, furthermore, that the constant I is zero for a reaction involving only liquids and solids, in agreement with the results of the preceding investigators, and finally that for gaseous reactions I can be regarded as the algebraic sum of a number of constants, each characteristic of a single substance, and capable of being calculated by a method suggested vaguely by Le Chatelier, involving a consideration of the vapor pressure curve of the substance in question. It is evident that the question of calculating I from other data than those obtained from direct free energy measurements is one of great theoretical and practical importance, and it will be one of the chief purposes of this series of articles to investigate the laws which determin the value of this interesting quantity. ${ }^{1}$ It seems preferable, however, first to collect all the data concerning free energy at present available, rather than to form at the outset any theory which might prejudice these calculations. This is the plan which will be followed in the succeeding papers.

In conclusion, I wish to express my thanks to Dr. Merle Randall for valuable assistance in the preparation of this paper.

\title{
THE CONSTITUTION OF ALUMINATES.
}

BY EDWard G. Mahin, D. C. Ingraham and O. J. Stewart.

Received September 19, 1912.

The solubility of aluminium hydroxide in alkalin bases and the existence of several minerals containing aluminium oxide and other metallic oxides in apparently constant proportions, have led to the hypothesis that aluminium hydroxide is amphoteric in character, forming salts with acids as well as with bases. Upon this assumption "aluminic acid" may be supposed to be mono-, di- or tri-basic, forming salts, perhaps hydrated, of $\mathrm{H}^{+}, \mathrm{H}_{2} \mathrm{AlO}_{3}^{-}, \mathrm{H}_{2}^{++}, \mathrm{HAlO}^{--}$or $\mathrm{H}_{3}^{+++}, \mathrm{AlO}_{3}^{---}$. The corresponding salts might be written $\mathrm{M}, \mathrm{AlO}_{2} \cdot \mathrm{H}_{2} \mathrm{O}, \mathrm{M}_{2} \mathrm{HAlO}_{8}$ or $\mathrm{M}_{3} \mathrm{AlO}_{3}$. Spinel, a mineral typical of the natural aluminates, is represented by the formula $\mathrm{Mg}\left(\mathrm{AlO}_{2}\right)_{2}$. The reprecipitation of aluminium hydroxide from a solution of a hypothetical aluminate by the addition of an aluminium salt of a strong acid would be accomplished by such a reaction as

$$
\mathrm{AlCl}_{3}+{ }_{3} \mathrm{MAlO}_{2}+6 \mathrm{H}_{2} \mathrm{O} \longrightarrow{ }_{3} \mathrm{MCl}+4 \mathrm{Al}(\mathrm{OH})_{3} \text {. }
$$

: It must, however, be pointed out that the experimentaly data concerning specific beats may often be equally well expressed by widely different empirical equations, the use of which leads to very different values of $I$. For this teason, when the equation for the specific heat of a substance has once been chosen, it must be employed without modification in all other calculations involving that substance. 
The electrolysis of an aluminate solution yields oxygen and a precipitate of aluminium hydroxide at the anode. This would be the natural result of the discharge of an anion containing aluminium and oxygen:

$$
2 \mathrm{AlO}_{2}{ }^{-} \cdot 3 \mathrm{H}_{2} \mathrm{O} \longrightarrow 2 \mathrm{Al}(\mathrm{OH})_{3}+\mathrm{O} \text {. }
$$

No such compounds as those just discussed, of undoubtedly constant composition, have been isolated. That the hypothesis of aluminate salt formation does not take into account the well known colloidal nature of aluminium hydroxide is apparent, and that it is not in harmony with other properties of aluminium has seemed to us to be a point worthy of consideration.

Any element whose hydroxide is amphoteric must be characterized by the fact that neither metallic nor non-metallic properties are strongly emphasized. Aluminium hydroxide cannot have more than a very slight concentration of hydroxyl ions, even in a saturated solution, and the metal should not exhibit (chemically) metallic properties to any marked degree. Aluminium, however, occupies a place in the electrochemical series not far removed from the alkalin earth metals and the heat of formation of aluminium oxide is 380.2 cal., a figure sufficiently high to indicate a fairly positive metal.

Most of the investigations that have been made upon the aluminates have been directed towards a determination of the formulas that should correctly represent their composition. When a solution of an alkalin aluminate or a hydrosol of aluminium hydroxide is allowed to stand for some time, a precipitate is gradually produced, this consisting of a crystallin form of aluminium hydroxide or of hydrated aluminium oxide. No aluminate can be made to crystallize as such from a solution and investigations have necessarily been limited to the solutions themselves. Prescott $t^{1}$ decided that these solutions contained salts of the acid $\mathrm{HAlO}_{2}$. Noyes and Whitney, ${ }^{2}$ in order to determin whether this is merely an empirical formula, used the freezing-point method to decide between the formulas $\mathrm{NaAlO}_{2}$ and $\left(\mathrm{NaAlO}_{2}\right) n$. Upon the assumption that both sodium hydroxide and sodium aluminate are completely ionized, the solution of aluminium in sodium hydroxide would give the same freezing point as the sodium hydroxide alone, if the aluminate is $\mathrm{NaAlO}_{2}$, but a different freezing point if it is $\left(\mathrm{NaAlO}_{2}\right) n$. This is because two ions would be produced by one molecule of either sodium hydroxide or $\mathrm{NaAlO}_{2}$ but three ions from $\mathrm{Na}_{2} \mathrm{Al}_{2} \mathrm{O}_{4}$, four from $\mathrm{Na}_{3} \mathrm{Al}_{3} \mathrm{O}_{6}$, etc. The work of Noyes and Whitney showed that a solution of potassium hydroxide, 0.227 $N$, did not have its freezing point changed by dissolving $1 / 3,2 / 3$ or I gram atom of aluminium. A solution $0.465 N$ was not changed by $1 / 6,1 / 2$ or $2 / 3$ gram atom of aluminium and solutions of sodium hydrox-

${ }^{1}$ THIS JotrNal, 2, 27 (1880).

2 Z. physik. Chem., 15, 694 (1894). 
ide and potassium hydroxide, $0.5 \mathrm{II} N$ and $0.233 N$, respectively, were not changed by ${ }^{2} / 3$ or $1 / 2 \mathrm{mols}$, respectively, of aluminium or aluminium hydroxide. These figures would seem to indicate that the formula of the aluminate must be $\mathrm{MAlO}_{2}$, according to the above reasoning. We should remark, however, that this reasoning is valid only in case the aluminate in solution is hydrolyzed not at all or to an extent which is insignificant. By the hydrolysis of one molecule of NaAlO. there would be produced three particles that would have an influence upon the freezing point of the solution; two ions from the sodium hydroxide of hydrolysis and one molecule of "aluminic acid." Qualitatively, the hydrolysis of these solutions is quite evident on account of their strongly basic character and the fact that aluminium hydroxide precipitates after a short time. Investigations are now in progress in this laboratory concerning the extent of the hydrolysis.

When aluminium reacts with sodium hydroxide or potassium hydroxide a crystallin, hydrated aluminium oxide separates as the reaction proceeds and this substance has a very small solubility in strong acids or bases. The separation takes place more slowly in dilute than in concentrated solutions and there is, without doubt, a condition of equilibrium between colloidal and crystalloidal aluminium hydroxide. Hantzsch, ${ }^{1}$ using $0.125 N$ sodium hydroxide, dissolved aluminium according to the proportion $\mathrm{NaOH} / \mathrm{Al}=\mathrm{I} / \mathrm{I}$. The crystallin oxide (or hydroxide) appeared after many days. Hantzsch concluded that there is produced, by hydrolysis of sodium aluminate, a hydrosol of aluminium hydroxide, and that this then changes to the crystalloid which precipitates. He measured the conductivity of the solution at different periods of time, and found that the molecular conductivity continually increases. He considered that this indicates a fairly rapid hydrolysis, although no precipitate appeared within 96 hours. The following values were obtained for the molecular conductivity of solutions having different ratios of aluminium hydroxide to sodium hydroxide at a dilution of 8 liters:

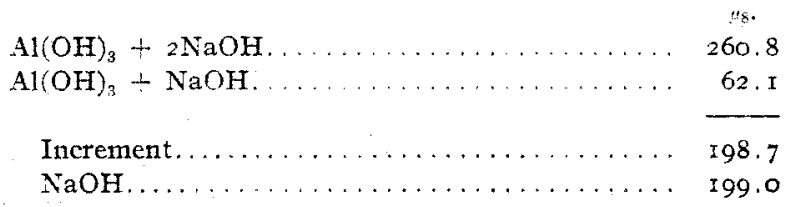

The conclusion of Hantzsch is that the aluminate must be represented by the formula $\mathrm{NaAlO}_{2}$.

Russ ${ }^{2}$ found that solutions of aluminium in sodium hydroxide ( $1:$ I .24), diluted to different specific gravities, precipitate at different rates. With a variation in specific gravity from I.OI3 to 1.570 , standing for 22 weeks,

'2. anorg. Chem, 30, 296 (1902).

Ibid., 4I, $216(1904)$, 
the maximum of aluminium oxide separated from the solution having a specific gravity I.39I.

Lyte, ${ }^{1}$ by a study of the reacting proportions of aluminium sulfate and sodium aluminate in solution, concluded that the latter is to be represented by the formula $\mathrm{Na}_{2} \mathrm{Al}_{2} \mathrm{O}_{4}$.

Herz $^{2}$ saturated sodium hydroxide, varying in concentration from $0.97^{\circ}$ $\mathrm{N}$ to $0.088 \mathrm{~N}$, and potassium hydroxide, $0.390 \mathrm{~N}$, with aluminium hydroxide and found in every case a solubility corresponding with the formula $\mathrm{M}_{3} \mathrm{AlO}_{3}$.

From an-inspection of the foregoing summary of results it is apparent that different methods of attack give results that indicate different formulas for the aluminates and that the quantitative relations between alkali metal and aluminium differ according to the method of making the solution, more aluminium being obtained in solution when the metal is used than is the case when aluminium hydroxide is dissolved. Indeed, it is scarcely to be expected that any constant relation could be observed, on account of the complex nature of a system that may contain free base, aluminate, hydrosol and a crystalloidal solution of aluminium hydroxide, and (later) hydrogel and crystallin aluminium hydroxide. That there is a very large hydrolysis of the aluminate is undoubted and that this hydrolysis is promoted by the colloidal character of one of the products of hydrolysis, as well as by the feebly acid character of this product, is equally beyond question. Whether the colloidal character of aluminium hydroxide is not responsible to a greater extent than its amphoteric character for its solubility in bases was the question that prompted the present investigation. This possibility was suggested by the chemical properties of aluminium, mentioned in the first part of this paper. It is a well known fact that the formation of hydrosols is often favored by the presence of an acid or a base; also that the sign of the electrical charge existing upon the colloidal particle may be changed by such addition. Thus the albumens and many other natural colloids are charged positively in acid solutions and negatively when a base is present, probably because of the adsorption of hydrogen ions in the one case and of hydroxyl ions in the other. The change of the positive colloid, aluminium hydroxide, to the negatively charged particle in solution might be due to the adsorption of an unusual amount of the hydroxyl ion, as well as to the formation of an anion of a salt. The discharge of the adsorbed ion by electrolysis would then precipitate (flocculate) aluminium hydroxide and liberate oxygen just as the discharge of such an anion as $\mathrm{AlO}_{2}^{-}$would form these products by the reaction

$$
4\left(\mathrm{AlO}^{-}\right) \rightarrow 2 \mathrm{Al}_{2} \mathrm{O}_{3}+\mathrm{O}_{2} \text {. }
$$

2 Chem. News, 5I, I09 (1885).

$2 Z$, anorg. Chem., 25, I55 (1900). 
From its place in the electrochemical series aluminium should form a fairly strong base and its acid forming properties should be slight. Aluminium hydroxide is said to be a very weak base because its salts with mineral acids are largely hydrolyzed and because of its solubility in strong bases. But ammonium hydroxide was also thought to be a weak base until Hantzsch showed that its basic character is masked by the fact that in solution there is a relatively small concentration of ammonium hydroxide in equilibrium with a large concentration of non-hydrated ammonia. Similarly, any solution of aluminium hydroxide contains but a small proportion of the total amount in the form of the crystalloidal base in equilibrium with the hydrosol, and this small amount has a very slight solubility.

The questions that we have attempted to answer are: (1) Is aluminium hydroxide amphoteric or is it really a strong base of very small solubility as a crystalloid? (2) Does the solution in alkalin bases contain a salt of "aluminic acid" or is it merely a colloidal solution, the solubility being increased by the presence of many hydroxyl ions? We have already remarked that the work of Noyes and Whitney is not indicative of salt formation, since the hydrolysis of the salt would produce a greater lowering of freezing point than would an equivalent amount of the original base. Their results are consistent with the hypothesis of a hydrosol of aluminium hydroxide, made possible by the presence of the soluble base. The increase of conductivity with time, as found by Hantzsch, is also to be expected, as the hydrosol gradually changes to a supersaturated solution of a crystalloid.

\section{Experimental.}

I. Heat of Solution of Aluminium Hydroxide in Bases.-If the act of solution in a base is an act of neutralization of an acid there should be a quantity of heat liberated that would be easily measurable. If, on the other hand; there is only the passage of a gel into a sol, it might be expected that the heat of sol formation would be relatively small. This heat of solution should not be confused with the heat of solution of metallic aluminium in bases, which was found by Hantzsch ${ }^{1}$ to be considerable; for the heat of solution in this case includes also the heat of formation of aluminium oxide.

The aluminium hydroxide used in these experiments was precipitated from a solution of potassium alum by ammonium hydroxide, washed free from sulfates and dried under diminished pressure over calcium chloride. Its composition was then $\mathrm{IAl}_{2} \mathrm{O}_{3}: 10,668 \mathrm{H}_{2} \mathrm{O}$, The reaction was accomplished in an Ostwald calorimeter, ${ }^{2}$ so arranged as to require little contact with the operator. The aluminium hydroxide was placed in a glass

1 Loc. cit.

2 Ostwald-Luther. Physiko-Chemische Messungen, 3rd. ed., 305. 
cup, suspended within the calorimeter in such a manner that it could be emptied into the solution of base without opening the calorimeter. An automatic stirrer was used and the whole apparatus was enclosed within a pasteboard covering. A Beckmann freezing-point thermometer was used, readings being made by means of a cathetometer. The whole apparatus was allowed to stand for five hours. Readings were then made for five consecutive minutes, these readings being: $2.496,2.494$, $2.493,2.49 \mathrm{I}, 2.49 \mathrm{I}^{\circ}$. Then $0.2024 \mathrm{~g}$. of substance (containing 0.0378 g. $\mathrm{Al}$ ) was added to $200 \mathrm{cc}$. of $7.452 \mathrm{~N} \mathrm{NaOH}$, and readings were taken at one minute intervals, as follows: $2.482,2.480,2.475,2.475$, $2.474,2.472,2.470,2.468,2.465,2.463,2.460,2.458,2.456,2.453$, $2.450,2.448,2.446,2.443,2.440^{\circ}$.

Solution took place rather slowly, partly on account of a partial change of aluminium hydroxide to the crystalloidal form during the drying process. The curve, Fig. I, shows that there was a regular rise in tempera-

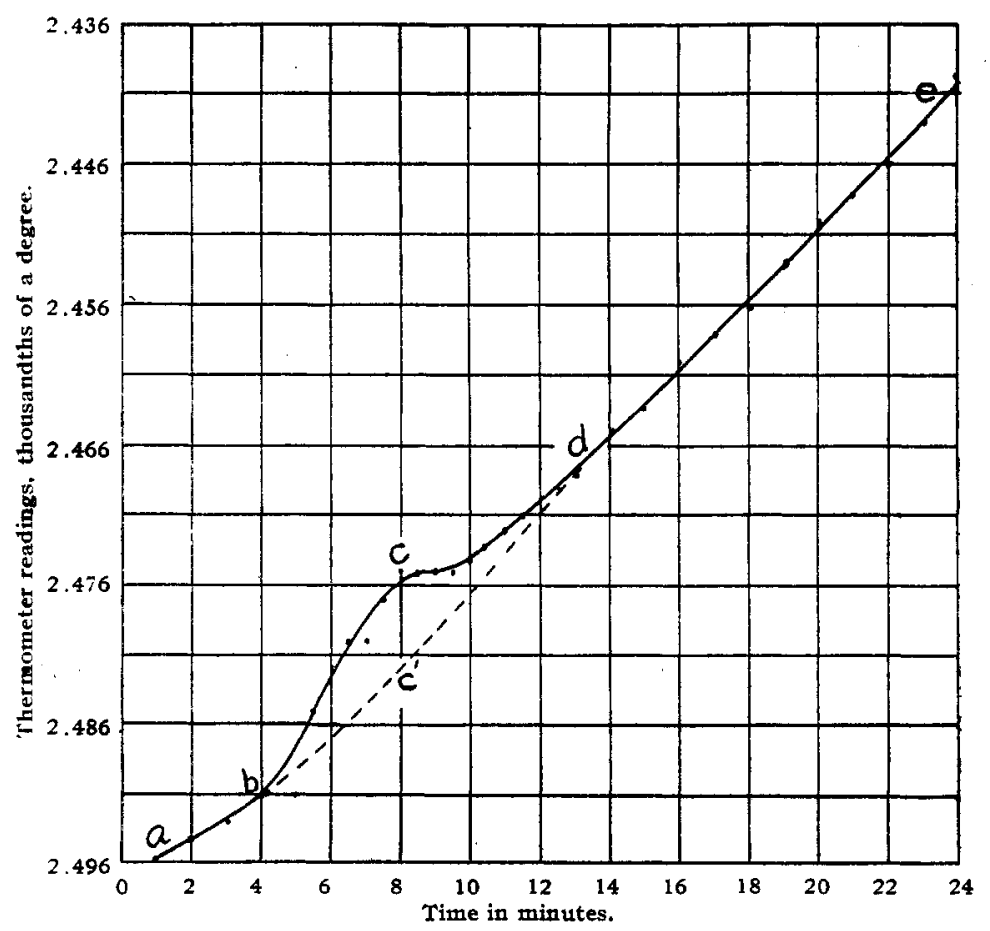

Fig. I.

ture, due to fluctuation in room temperature, and that there was a relatively slight interruption of the regular rise, due to the solution of the powder. The dotted line, $b, c^{\prime}, d$, represents the assumed course of the curve, had the powder not been introduced. The maximum change in 
temperature due to heat of solution, which is approximately given by the distance, $c, c^{\circ}$, was $0.0065^{\circ}$. The other data and the calculated values are as follows:

Specific heat of solution 0.874

Water equivalent of solution, calories 174.8

Water equiyalent ố glass cup, calorie

Water equivalent of inner vessel and stirrer, calories.

10.07

Heat of solution of 0.2024 gram powder, calories

Calculated heat of solution of powder containing 27 grams of aluminium, calories

864.0

The solution of one mol of aluminium hydroxide thus involves the evolution of 864 calories. That this figure is, at best, only a rough approximation is all that is claimed. It does show, however, that the energychange is very small.

2. Action of Ammonium Nitrate upon a Solution of Sodium Aluminate. -Assuming that the formula $\mathrm{NaAlO}_{2}$ represents the composition of sodium aluminate, the following equations show the possible course of the reactions with ammonium nitrate:

$$
\begin{aligned}
& \mathrm{NH}_{4} \mathrm{NO}_{3}+\mathrm{NaAlO}_{2} \longrightarrow \mathrm{NH}_{4} \mathrm{AlO}_{2}+\mathrm{NaNO}_{3} . \\
& \mathrm{NH}_{4} \mathrm{AlO}_{2}+2 \mathrm{HOH} \longrightarrow \mathrm{NH}_{4} \mathrm{OH}+\mathrm{Al}(\mathrm{OH})_{3},
\end{aligned}
$$

the ratio in mols being $\mathrm{NH}_{4} \mathrm{NO}_{3} / \mathrm{Al}_{2} \mathrm{O}_{3}=2 / \mathrm{I}$. If the composition of the aluminate is $\mathrm{Na}_{3} \mathrm{AlO}_{3}$ the following reactions would take place:

$$
\begin{aligned}
& { }_{3} \mathrm{NH}_{4} \mathrm{NO}_{3}+\mathrm{Na}_{3} \mathrm{AlO}_{3} \longrightarrow\left(\mathrm{NH}_{4}\right)_{3} \mathrm{AlO}_{3}+{ }_{3} \mathrm{NaNO}_{3}, \\
& \left(\mathrm{NH}_{4}\right)_{3} \mathrm{AlO}_{3}+3 \mathrm{HOH} \longrightarrow{ }_{3} \mathrm{NH}_{4} \mathrm{OH}+\mathrm{Al}(\mathrm{OH})_{3},
\end{aligned}
$$

the molecular ratio being $\mathrm{NH}_{4} \mathrm{NO}_{3} / \mathrm{Al}_{2} \mathrm{O}_{3}=6 / \mathrm{I}$. If, on the other hand, aluminium hydroxide is held in the form of a sol by the adsorption of hydroxyl ions from sodium hydroxide, ammonium nitrate will precipitate the former by causing hydroxyl ions to disappear according to the reaction:

$$
\mathrm{NH}_{4} \mathrm{NO}_{3}+\mathrm{NaOH} \longrightarrow \mathrm{NaNO}_{3}+\mathrm{NH}_{4} \mathrm{OH} \text { (unionized). }
$$

In this case the ratio of ammonium nitrate to aluminium oxide may not correspond with any definit formula or even have any constant value. To investigate this point aluminium was dissolved in sodium hydroxide solution, approximately $5 \mathrm{~N}$, until a precipitate appeared, the solution being then diluted ten times and filtered in an apparatus from which carbon dioxide was excluded. A platinum anode and aluminium cathode were then placed in the solution, and a current passed until aluminium hydroxide began to deposit on the anode. The solution was again filtered. Pure ammonium nitrate was dried until the weight was constant. After a known weight of the latter had acted upon a measured volume of the aluminate solution (carbon dioxide excluded) the precipitated aluminium hydroxide was filtered, using a pump to remove the greatest 
possible amount of adhering solution so that hydrolysis during washing could not precipitate more hydroxide upon the filter.

Table I gives the results of these experiments.

TABLE I.

\begin{tabular}{|c|c|c|c|c|}
\hline Exp. No. & Cc. used. & $\begin{array}{l}\mathrm{NH}_{4} \mathrm{NO}_{3} . \\
\text { Granis. }\end{array}$ & $\begin{array}{l}\mathrm{Al}_{2} \mathrm{O}_{2} . \\
\mathrm{Grams}\end{array}$ & $\mathrm{NH}_{4} \mathrm{NO}_{3} / \mathrm{Al}_{2} \mathrm{O}_{3}$ \\
\hline $\mathbf{I}$ & 20 & 0.1216 & 0.0823 & I. $885 / I$ \\
\hline 2 & 20 & 0.6791 & 0.3235 & $2.6785 / I$ \\
\hline 3 & Io & 0.1626 & 0.1077 & I. $530 / I$ \\
\hline
\end{tabular}

In the second experiment there was required slightly more than $2 / 5$ of the ammonium nitrate indicated by the formula $\mathrm{Na}_{3} \mathrm{AlO}_{3}$, while in the first and third experiments considerably less ammonium nitrate was required than is indicated by the formula $\mathrm{NaAlO}_{2}$.

3. Electrolysis of Sodium Aluminate.-The electrical charge borne by a colloid is presumably that of its adsorbed ion. Scientists still disagree as to whether the quantity of adsorbed ion is considerably less than or more than chemically equivalent to the mass of colloid in a dispersed system. There is at least a probability that there is no very definit relation between these quantities or any constancy in the relation between the mass of adsorbed ion discharged by a current and that of a gel flocculated by such discharge. If aluminates are definit salts, the relation between hydrogen and oxygen evolved and aluminium hydroxide precipitated should be constant and should provide a means for calculating the correct formula for the aluminate.

The solution to be electrolyzed was placed in the apparatus represented in Fig. 2. The cathode $K$ was of platinum foil and the anode $i$ of platinum wire. The cathode section being placed at a lower level than the anode section, mixing by diffusion was hindered, sodium hydroxide accumulating in the lower part of the apparatus. Much difficulty was experienced in preventing the solution of precipitated aluminium hydroxide by sodium hydroxide that could not be entirely excluded from the anode section. This solution was hindered to a still greater extent in the later experiments by placing a disk of filter paper over the lower end of the tube $e$, the anode coil being lowered only so far as to bring it just below the surface of the solution. The disk of paper being small,

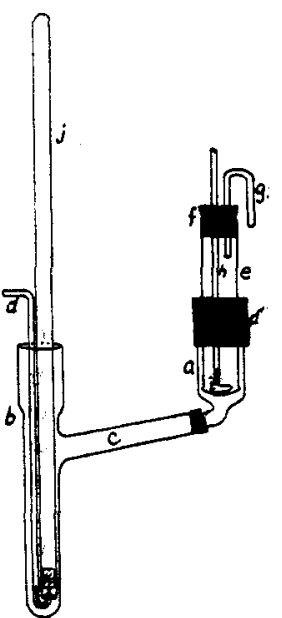

Fig. 2 . precipitation of more aluminium hydroxide by hydrolysis during washing was practically eliminated by absorbing the excess of solution by a pile of dry filter papers. Blank experiments were run so that allowance was made for the very slight amount still precipitated by this cause. 
The anode section was protected from carbon dioxide in all experiments by attaching a tube of soda lime at $g$.

The eudiometer $j$ was placed over the cathode for two reasons: ( $I$ ) The eudiometer could be removed to a glass cylinder for the purpose of measuring the gas evolved, without disturbing the precipitated aluminium hydroxide. (2) The volume of hydrogen being twice as great as that of oxygen, unavoidable errors in reading were less significant. The volume of oxygen was calculated from the observed volume of hydrogen and the weight of the former was then calculated, the necessary correetions being made for temperature, pressure and aqueous tension. In Table II are given the results of eighteen experiments:

TABLE II.

\begin{tabular}{|c|c|c|c|c|c|c|c|}
\hline No. & Method. & Hours. & Volts. & Amp. & $\underset{\mathrm{O}_{2} \times 10^{3}}{\text { Mols }}$ & $\underset{\mathrm{Al}_{2} \mathrm{O}_{3} \times 10^{3} .}{\text { Mols }}$ & $\mathrm{Al}_{2} \mathrm{O}_{3} / \mathrm{O}_{2}$ \\
\hline I & A & 12 & .. & . & I. 784 & 1.079 & $2 / 2,1834$ \\
\hline 2 & $\mathrm{C}$ & 14 & 31 & . & I. 0645 & I. 328 & $2 / 1.6024$ \\
\hline 3 & $C^{\prime}$ & 13 & 19 & . & o. 7644 & 0.9686 & $2 / 1 \cdot 5783$ \\
\hline 4 & $c^{\prime}$ & I0. 5 & 19 & . & 0.8806 & 0.6487 & $2 / 2.7 \times 47$ \\
\hline 5 & $\mathrm{C}^{\prime}$ & 13 & 19 & . & I. 1055 & I. 4190 & $2 / x \cdot 5662$ \\
\hline 6 & $D$ & Ir & 19 & . & 1.064 & I.9510 & $2 / 1.0908$ \\
\hline 7 & D & 8 & 19 & . & 0.9519 & I.910 & $2 / 0.9968$ \\
\hline 8 & D & 9 & 19 & .. & $0.5^{25} 6$ & I. 497 & $2 / 1.0401$ \\
\hline 9 & $\mathrm{E}$ & II & 19 & . & 0.5947 & 0.6095 & $2 / 1.9513$ \\
\hline 10 & $\mathrm{~F}$ & I4 & 19 & . & 0.3605 & 0.6008 & $2 / 1.2006$ \\
\hline II & $\mathrm{F}$ & 18 & 19 & . & 0.3864 & 0.6585 & $2 / 1,1736$ \\
\hline 12 & $E$ & Io & 19 & . & 0.6045 & 0.8239 & $2 / 1.4675$ \\
\hline$x_{3}$ & $\mathrm{E}$ & I $\mathrm{I}$ & 19 & . & 0.3919 & 0.6566 & $2 / 1.16 \mathrm{r} 2$ \\
\hline 14 & $E$ & 5.5 & 19 & $\ldots$ & 0.2984 & 0.455 & $2 / 1.3118$ \\
\hline 15 & $\mathrm{G}$ & I & 40 & 0.04 & 0.4749 & I.069 & $2 / 0.8658$ \\
\hline 16 & $G$ & I & 44 & 0.05 & 0.4617 & 0.8787 & $2 / 1.0509$ \\
\hline 17 & $\mathrm{G}$ & 2 & 43 & 0.03 & 0.4057 & 0.8845 & $2 / 0.9174$ \\
\hline 18 & $\mathrm{G}$ & 4 & 43 & 0.03 & 0.5079 & 0.9100 & $2 / 1 \cdot 1164$ \\
\hline \multicolumn{7}{|c|}{ Calculated for $\mathrm{Na}_{3} \mathrm{AlO}_{3}$. } & $2 / 3$ \\
\hline
\end{tabular}

Description of methods:

A. Aluminium foil was dissolved in sodium hydroxide. This solution was not saturated with aluminium, as no deposition of a precipitate occurred until two hours after electrolysis was begun.

C. Solution A was saturated by passing a current, using a platinum anode and aluminium cathode.

$C^{\prime}$. Solution $C$ used in the experiments; a soda lime tube was used to exclude carbon dioxide from the cathode section of the decomposition apparatus.

D. Same solution as in C. During the decomposition the anode was enclosed in a capsule of filter paper.

E. Same solution as in C. The filter capsule of $D$ was replaced by a glass tube $e$ (Fig. 2), over the lower end of which was secured, by means of a rubber band, a piece of extracted filter paper.

F. Same solution and experiment as $\mathrm{E}$ except that the tube $e$ was also surrounded by a filter capsule. 
G. Same solution and experiment as E except that the aluminium hydroxide was removed after about $5 \mathrm{cc}$. of hydrogen had been collected, the anode replaced and the process continued until another $5 \mathrm{cc}$. had been collected, and so on until the end of the experiment.

In every case the precipitated aluminium hydroxide possessed at first the appearance of a colloidal gel, changing to the crystallin modification as the experiment proceeded. It has already been pointed out that it was impossible to entirely prevent the solution of the precipitate in the base which was unavoidably present in the anode section. In spite of this fact there was obtained, in experiments $7,1_{5}$ and 17 , a ratio of aluminium oxide to oxygen that would be impossible for any formula that has been suggested for sodium aluminate. With further refinements in methods of carrying out electrolytic decomposition, we may expect to obtain still larger ratios.

\section{Summary.}

Known properties of aluminium have indicated a doubt as to whether aluminium hydroxide is amphoteric. An examination of previous cryoscopic investigations has strengthened this doubt. Measurements of the heat of solution of aluminium hydroxide in sodium hydroxide, of the quantitative relations between ammonium nitrate and sodium aluminate and observations made upon the electrolysis of sodium aluminate indicate that the colloidal properties of aluminium hydroxide play a far more important part in conditioning its solubility in bases and there is at least room for doubt as to whether "aluminates," as definit salts, exist at all.

The work is being continued and solutions of "zincates" will also be investigated.

Chemical Laboratory of Purdue University, LAFAYETTE, IND., June, 1912.

[CONTRIBUTION FROM ThE CheMICAL, Laboratory OF THE UNIVERSity OF ILLINOIS.] HETEROGENEOUS EQUILIBRIA BETWEEN AQUEOUS AND METALLIC SOLUTIONS. [SECOND PAPER.]

THE INTERACTION OF MIXED SALT SOLUTIONS AND LIQUID AMALGAMS. By Groroe McPhajl Suith.

Received November 5, 1912.

The Ionization Relations of Sodium and Potassium Salts in Mixtures. I.

Contents: x. Purpose of the Investigation. 2. Principles relating to the Ionization of Salts in Mixtures. 3. The Experimental Method. 4. The Experimental Data. 5. Method of Calculation and Results. 6. Discussion of the Results.

I. Purpose of the Investigation.-The general purpose of the investigation was to study, by means of an independent method, ${ }^{1}$ the ionization

${ }^{1}$ Cf. Thrs Journal, 32, 502 (1910); Z. physik. Chem., 73, 424 (19ro). 